Supporting information

\title{
Enhanced hydrogen storage capacity of high surface area zeolite-like carbon materials
}

\author{
Zhuxian Yang, Yongde Xia, and Robert Mokaya* \\ School of Chemistry, University of Nottingham, Nottingham, NG7 2RD, UK
}



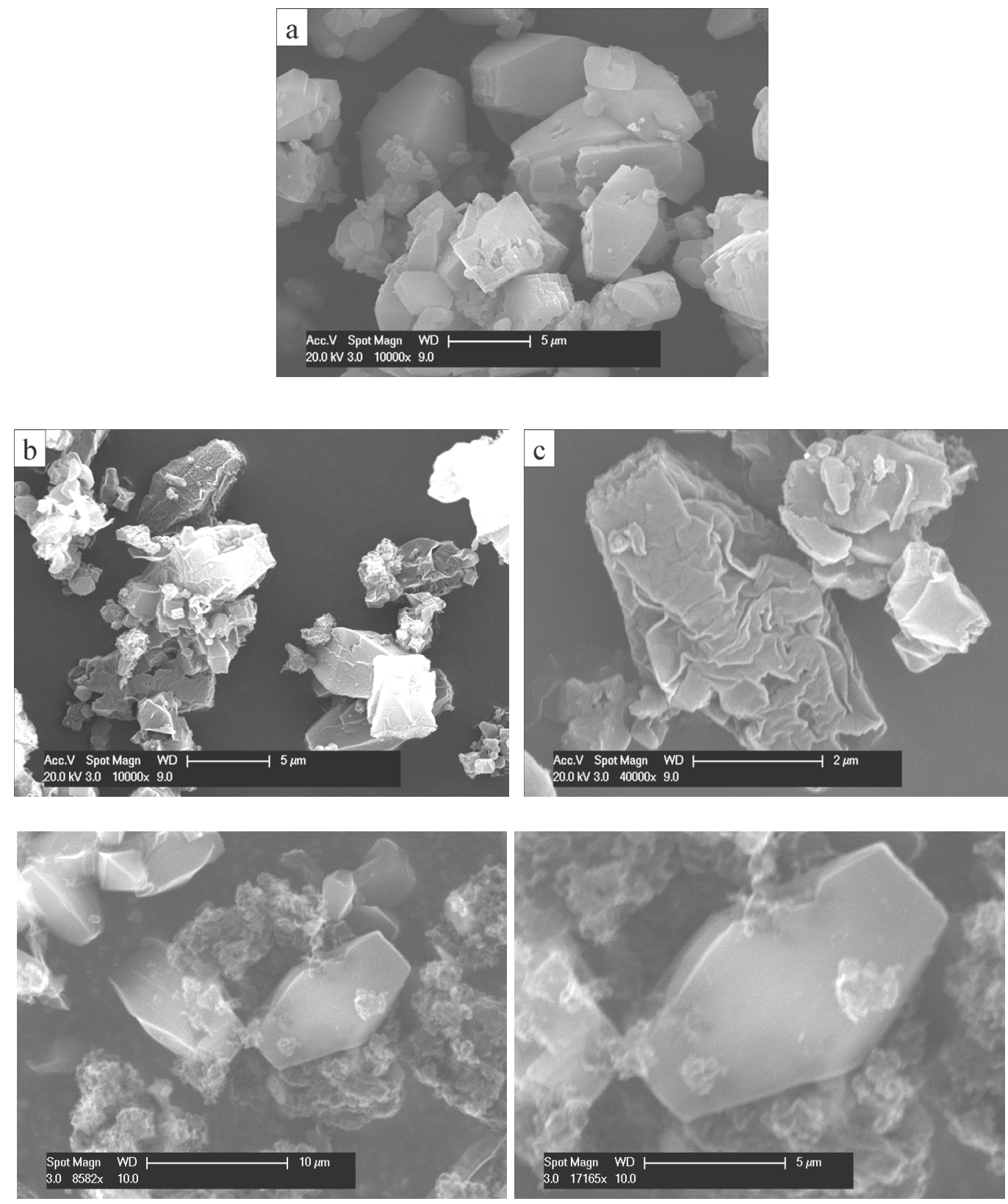

Supporting Figure 1S. Representative SEM images of (a) zeolite $\beta$ and two carbon samples prepared at CVD temperature of $850{ }^{\circ} \mathrm{C}$. The carbon samples were prepared via a procedure whereby the carbon source (acetonitrile) was in contact with the zeolite templates during both the temperature ramping process and the final heating step at $850{ }^{\circ} \mathrm{C}$. The middle images $(\mathrm{b}, \mathrm{c})$ are for one sample and the bottom images are for the second sample. 


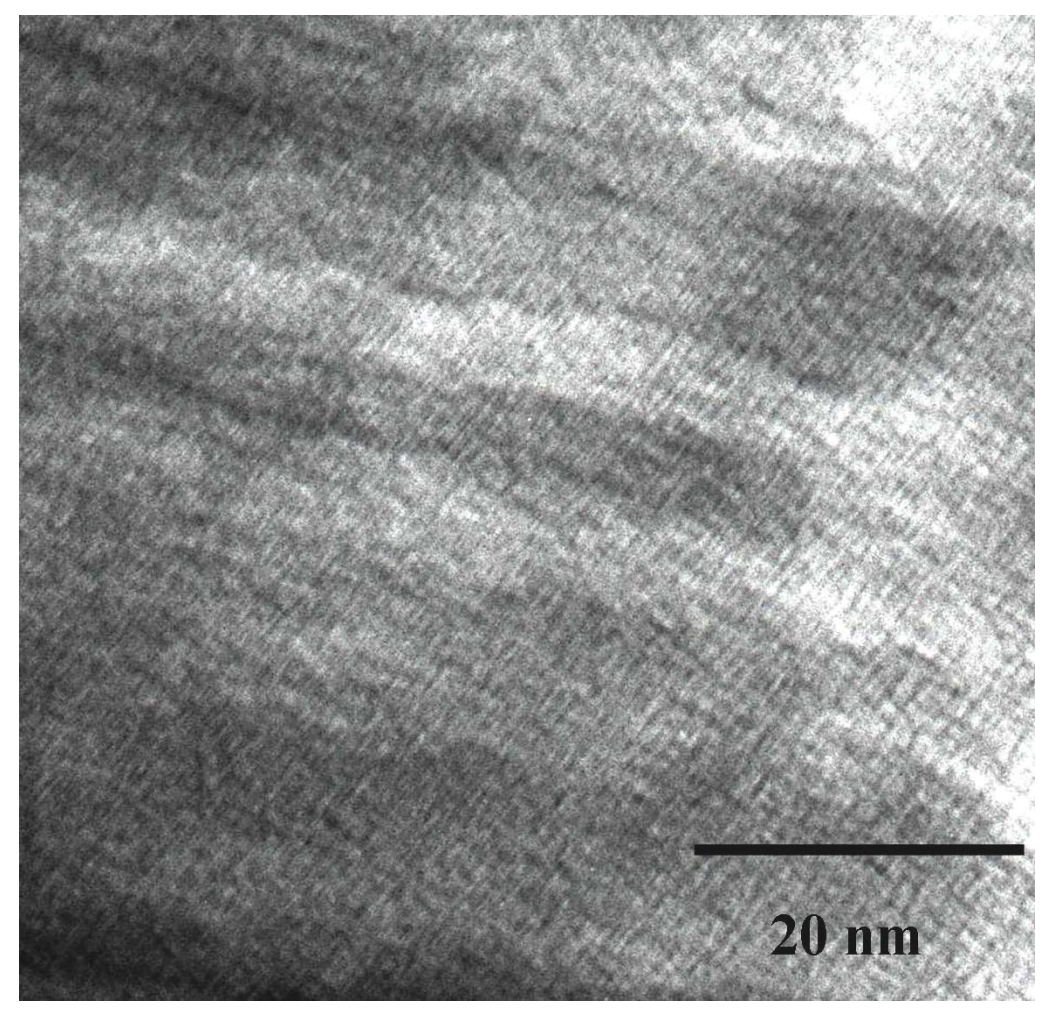

Supporting Figure 2S. Representative TEM image of zeolite templated carbon material (CA850) prepared at CVD temperature of $850{ }^{\circ} \mathrm{C}$. 


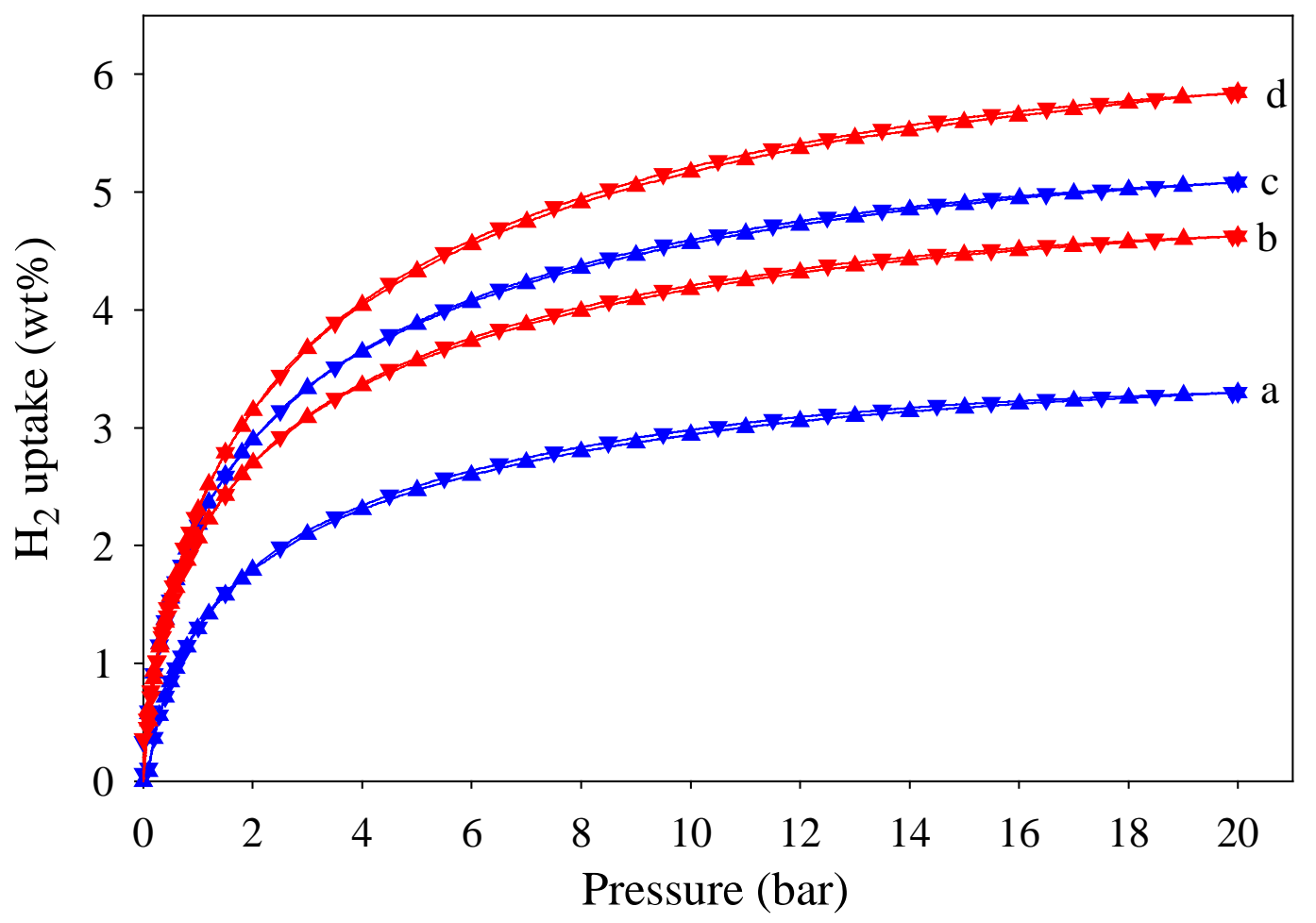

Supporting Figure 3S. Hydrogen sorption isotherms at $-196{ }^{\circ} \mathrm{C}$ of carbons obtained via CVD using zeolite $\beta$ as template and acetonitrile as carbon precursor (a) CA800, (b) CB850, (c) CA850, (d) CB850h. (Carbon density of $1.5 \mathrm{~g} / \mathrm{cm}^{3}$ was used and no buoyancy correction was applied for adsorbed $\mathrm{H}_{2}$ ). 
Langmuir plots were used to estimate the maximum uptake of supercritical hydrogen $\left(\right.$ at $\left.-196{ }^{\circ} \mathrm{C}\right)$.

$$
\frac{P}{W}=\frac{1}{W_{0}} P+\frac{1}{W_{0} \bullet K} \quad W_{0}=\frac{1}{a}
$$

$W$ is the degree of adsorption at a pressure of $P, W_{0}$ is the saturated adsorption and $K$ is a coefficient.
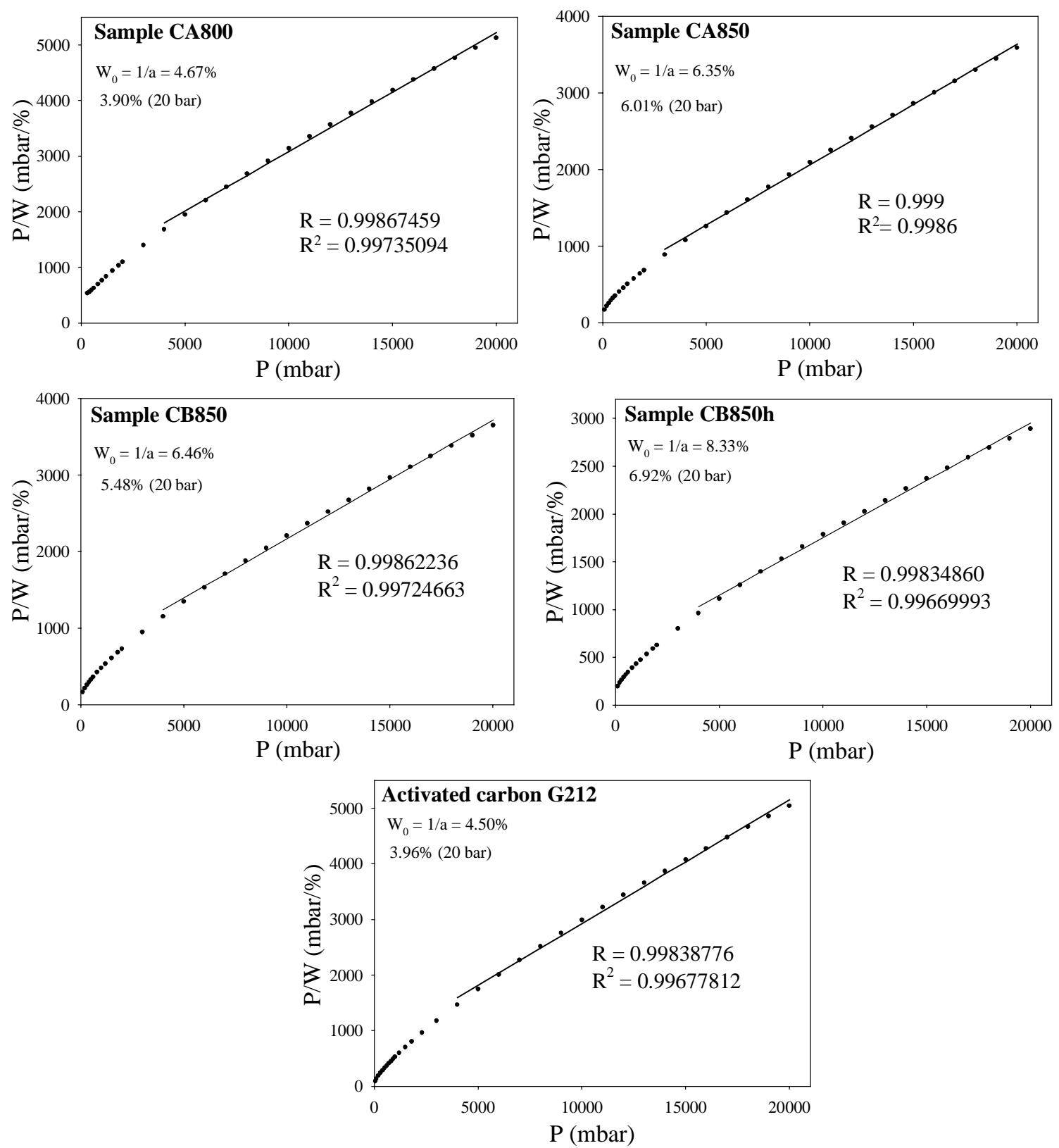

Supporting Figure 4S. Langmuir fitting for $\mathrm{H}_{2}$ adsorption on zeolite-templated carbon materials and activated carbon G212. 


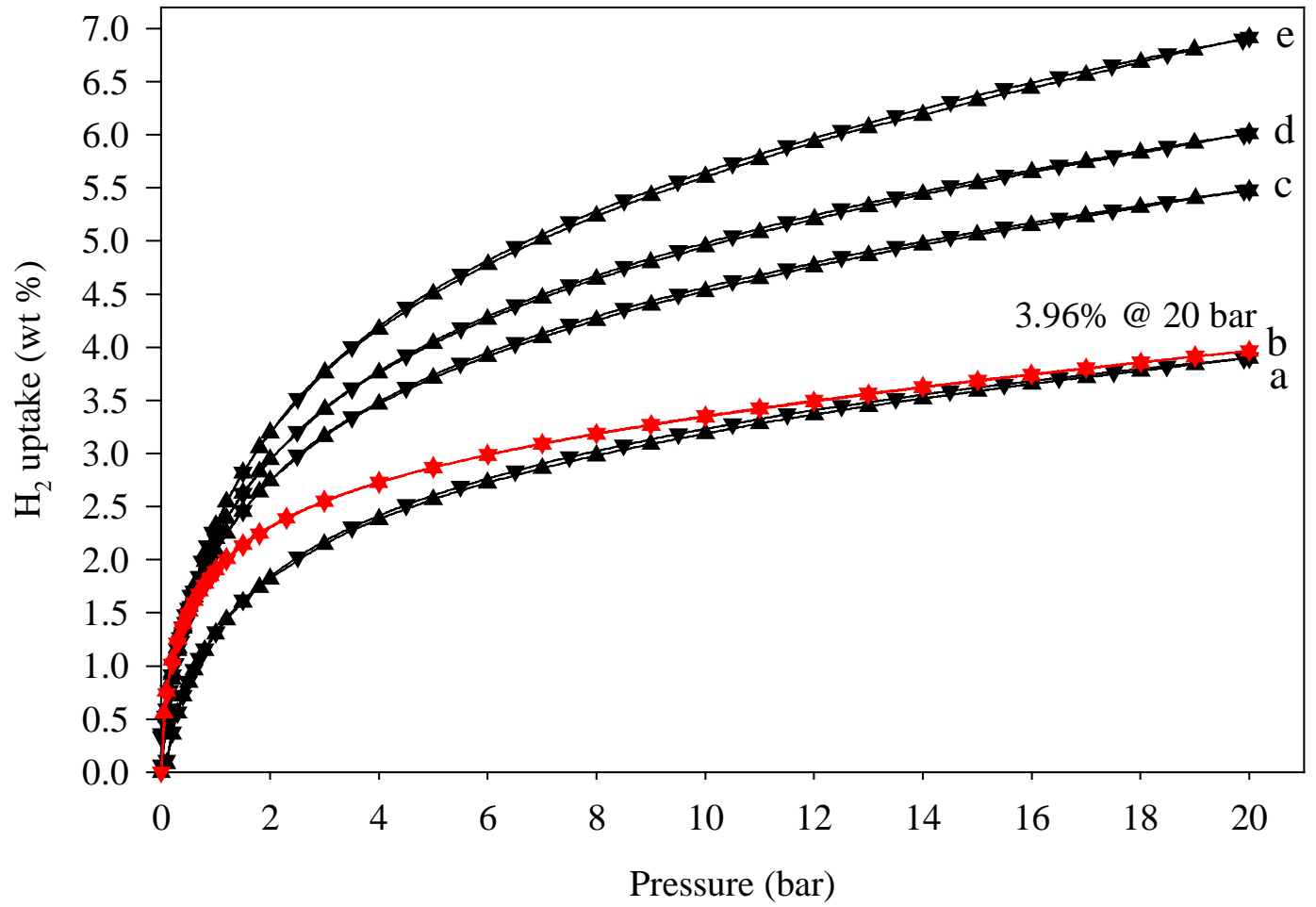

Supporting Figure 5S. Hydrogen sorption isotherms at $-196{ }^{\circ} \mathrm{C}$ of (b) activated carbon G212 (in red) and our carbon samples (a) CA800, (c) CB850, (d) CA850, (e) CB850h. Carbon density of $1.8^{*}$ and $1.5 \mathrm{~g} / \mathrm{cm}^{3}$ was used for G212 and our samples respectively, and hydrogen density of 0.04 $\mathrm{g} / \mathrm{cm}^{3}$ was used for buoyancy correction of adsorbed $\mathrm{H}_{2}$. (*Zhao, et al, J. Phys. Chem. B, 2006, $110,8880)$. 


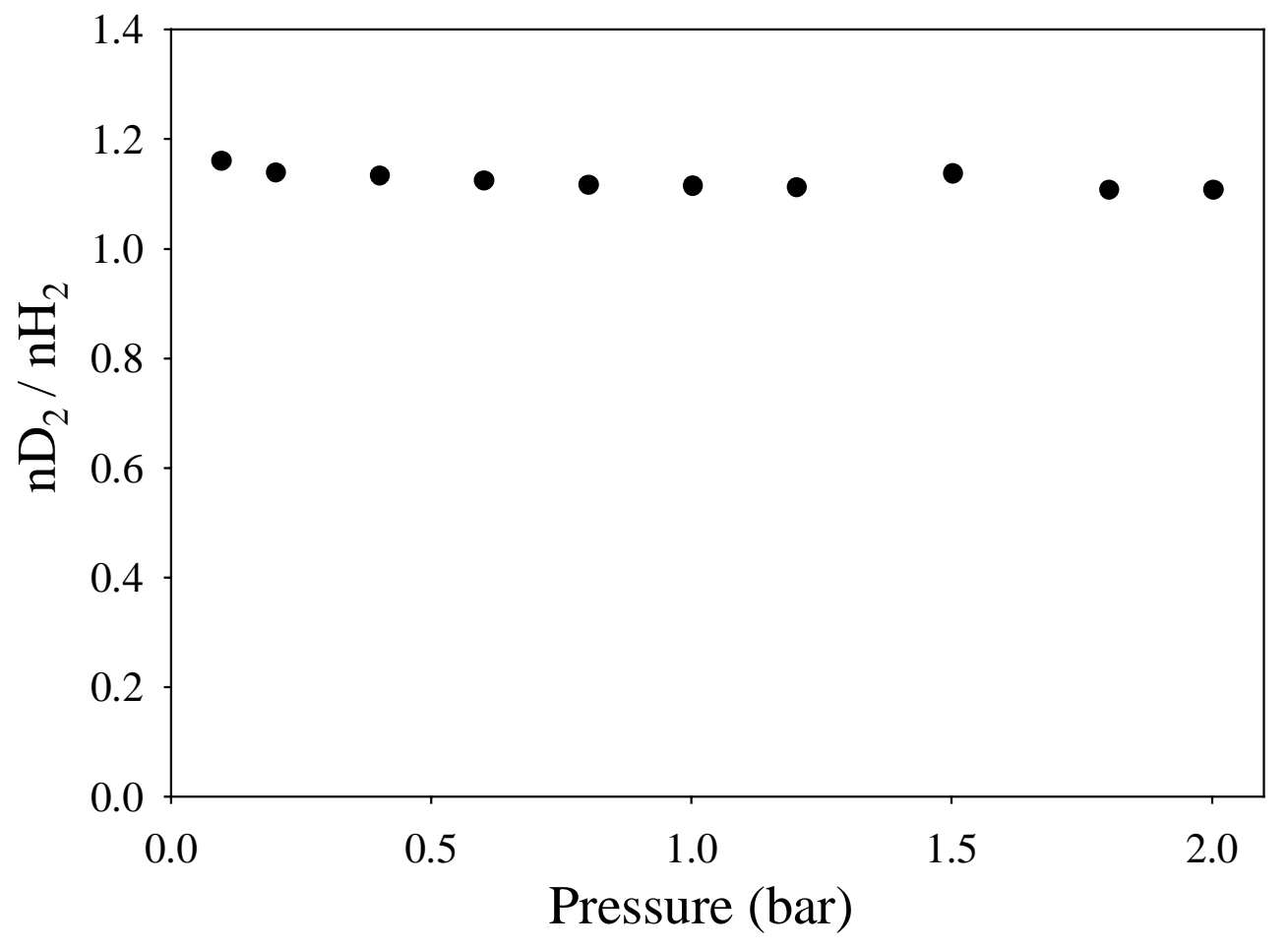

Supporting Figure 6S. The variation of the ratio of amounts adsorbed (molar $\mathrm{nD}_{2} / \mathrm{nH}_{2}$ ratio) with pressure for sample CA850. 
The isosteric heat of adsorption $\left(Q_{\mathrm{st}}\right)$ can be calculated using hydrogen-adsorption isotherms measured at different temperatures based on the Clausius-Clapeyron equation (1).

$\left(\frac{\partial \ln P}{\partial T}\right)_{\theta}=\frac{Q_{s t}}{R T^{2}}$

Where $\theta$ is the fraction of the adsorbed sites at a pressure $P$ and temperature $T, R$ is the universal gas constant.

In this study, the $Q_{\text {st }}$ was calculated using hydrogen-adsorption isotherms measured at -196 ${ }^{\circ} \mathrm{C}$ (liquid nitrogen) and $-186{ }^{\circ} \mathrm{C}$ (liquid argon). For a certain $\theta$ value (adsorbed amount as wt $\%), Q_{s t}$ was calculated by applying the integral format of the Clausius-Clapeyron equation (2).

$\ln P_{2}-\ln P_{1}=\frac{Q_{s t}}{R}\left(\frac{1}{T_{1}}-\frac{1}{T_{2}}\right)$

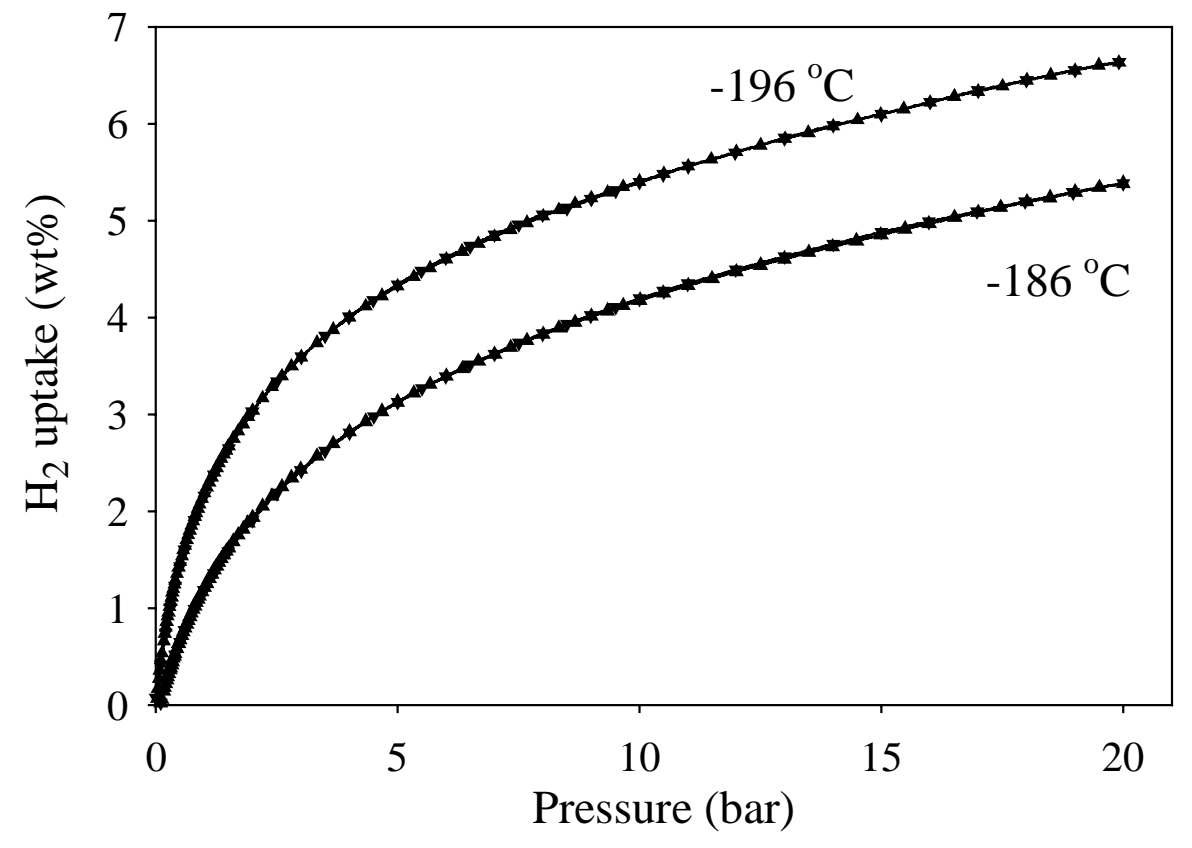

Supporting Figure 7S. Hydrogen sorption isotherms (adsorption ( ) and desorption ( ) at $196{ }^{\circ} \mathrm{C}$ and $-186{ }^{\circ} \mathrm{C}$ of sample $\mathrm{CB} 850 \mathrm{~h}$ used to calculate isosteric heat of adsorption. 